In addition, two Cuban psychiatrists are in The Gambia on secondment for a period of 3 years at a time. The national totals of other mental health workers are: psychiatric nurses (trained), 1; registered nurses working in psychiatry, 2; enrolled nurses in psychiatry, 4; nursing assistants working in psychiatry, 18; psychologists, 0; occupational therapists (untrained), 2; mental health social workers, 0; traditional healers specialising in mental health, 12.

\section{Local health beliefs}

The traditional healers in The Gambia believe that what psychiatry calls 'mental illness' is the manifestation of a bewitchment invoked by another human, or a djinn using a charm. There is a belief that the world is populated by djinns as well as humans. Djinns are other living beings which most humans cannot see; they may or may not believe in God, and the non-believing djinns may be troublesome towards humans and use charms on them. Treatment used by traditional healers include verses of the Quran inscribed on paper, washed in water, which is then drunk by the patient. Herbal remedies are also applied.

\section{Mental health legislation}

The Suspected Lunatic Detention Act 1964 is still in use in The Gambia. In 2004 The Gambia's Department of State for Health and Social Welfare recognised that the Act is outdated and fails to address the human rights of those with mental disorders. A mental health policy and strategic action plan were drafted in 2006, outlining how to narrow the gap in mental health services. The official implementation of the policy is still awaited but initial steps have been taken to appoint a mental health coordinator. The government pledged to draft and implement new mental health legislation incorporating patient confidentiality, informed consent, equal opportunity for care, conditions in facilities, appropriate care using the least restrictive methods, safeguards against abuse, and equal opportunities for employment, housing and justice.

\section{Sources}

Nyan, O., Mendy, A. M., Moraru, D., et al (2011) Diagnostic characteristics of inpatients in a Western African psychiatric hospital. World Journal of Biological Psychiatry, 12, 85-88.

United Nations Development Programme (2011) International Human Development Indicators. Available at http://hdrstats.undp. org/en/indicators/103106.html (accessed March 2012).

van der Sande, M. A. B., Inskip, H. M., Jaiteh, K. O., et al (2001) Changing causes of death in the West African town of Banjul, 1942-97. Bulletin of the World Health Organization, 79, 133-141.

World Health Organization (2007) Gambia Summary. Mental Improvement for Nations Development. Available at http://www.who.int/mental_health/policy/country/ GambiaSummary_7May2007NOPics.pdf (accessed March 2012).

World Health Organization (2009) Country Cooperation Strategy: The Gambia. Available at http://www.who.int/countryfocus/ cooperation_strategy/ccsbrief_gmb_en.pdf (accessed March 2012).

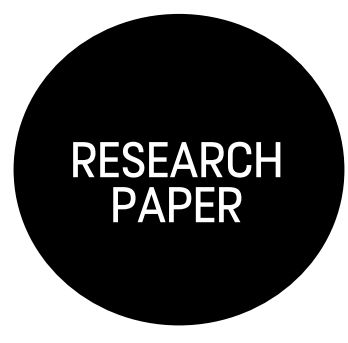

\title{
Relationship of psychosocial adversity to depressive symptoms and self-harm in young homeless people
}

\author{
Balamurugan Nambi ${ }^{1}$, Pallab Majumder ${ }^{2}$ and Panos Vostanis ${ }^{3}$
}

'Senior Trainee in Child Psychiatry, Leicestershire Child and Adolescent Mental Health Service, UK

${ }^{2}$ Lecturer in Child Psychiatry, University of Leicester, UK

${ }^{3}$ Professor of Child Psychiatry, University of Leicester, Greenwood Institute of Child Health, Leicester, UK, email pv11@le.ac.uk
An increased incidence of psychiatric disorders has been reported in homeless young people. These disorders are often related to their childhood experience of trauma, although less is known about how secondary traumatic experiences while being homeless affect psychopathology. The aim of this study was to establish the relationship between life adversities - living on the street, physical and sexual abuse (during both childhood and young adult life) and substance misuse - and depressive symptoms and self-harm among homeless young people.
The number of homeless people worldwide has grown steadily in recent years. Accurate statistics are difficult to gather; however, UNICEF estimates there are approximately 100 million street children worldwide, with that number constantly growing (see Kanth, 2004). Interventions and service provision for homeless adolescents and young adults with psychiatric disorders remain a challenge to mental health services because of the complexities surrounding the assessment of this population. The situation can be worsened by stigma associated with mental illness. The difficulty for them to ask for help partly remains with them and partly within the service structure. 
We are grateful to the young people who took part in this study. Our special thanks to the five mental health coordinators, the Foyer shelters managers and staff, and to Helen Taylor for the data collection. This project was funded by the Gatsby Foundation.
Exposure to any type of abuse (physical, sexual or emotional) in early life can increase the likelihood of young people running away from the family home and being accommodated in care. This in turn makes them more vulnerable to poor psychological adjustment, depression, substance misuse and suicidal behaviour (Kimberly et al, 2000; Tyler, 2006). It is well established that adverse life experiences during childhood, particularly those involving family breakdown, in conjunction with inadequate substitute care and resulting stressors and rejections, make young people more vulnerable to depression and other forms of psychopathology (Herman et al, 1994).

In summary, previous research has shown the multitude and complexity of mental health problems among young homeless people and their relationship with various adverse social factors. There is limited understanding of the impact of such adverse factors from young people's earlier upbringing, the secondary effects of being homeless and the nature of the relationship between adverse experiences and mental health problems. The rationale for this study was to explore the nature of these relationships rather than to suggest any causal association between the adversities and mental disorders.

\section{Method}

The study was conducted in a network of shelters for homeless young persons called Foyers. It currently has 132 shelters (Foyers) across the UK that provide accommodation and preparation for homeless people aged 16-25 years. These are interlinked under the Foyer Federation's international accreditation scheme. Out of these 132, 18 shelters from four UK regions (the South West, West Midlands, East Midlands and North East) were chosen to be provided with access to a pilot in-house designated mental health service. Over 1 year, 150 young homeless people were referred to this mental health service and they constituted the sample for this study. Ethical approval for the study was obtained from the multicentre National Health Service research ethics committee. Informed written consent was obtained and none of the participants refused to participate in the study. More than half of the referrals $(62.4 \%)$ were made by staff at the shelters. Young people's mean age was 19.0 years (range 16-25 years); $53.3 \%$ were male and $46.7 \%$ female. Most of them $(86.7 \%)$ were White British; $4.0 \%$ were mixed race, $1.3 \%$ Black Caribbean, 1.3\% Black African, 2.0\% Black British and $4.7 \%$ from other ethnic groups.

The mental health service systematically collected data on behalf of the research team at the point of first assessment for each young person referred. The young people were rated for their depression and self-harm according to the Health of the Nation Outcome Scales (HoNOS), a standardised and well established assessment and outcome measure specifically developed for use by mental health practitioners (Wing et al, 1998). The HoNOS was scored following interviews with the young people in the study sample. The instrument assesses a range of mental health needs. One of the 12 items is depressed mood. Each HoNOS item is rated on a five-point severity scale (Wing et al, 2000): 0, no problem; 1, minor problem requiring no action; 2, mild problem but definitely present; 3 , moderately severe problem; 4 , severe to very severe problem. Accordingly, we considered 0 and 1 on the severity scale of depression as being of no clinical significance, and a score of 2-4 as requiring a clinical assessment and possible treatment. A service checklist was also completed on young people's history, risk behaviours and service contacts.

We initially analysed the descriptive statistics of the adverse life events and mental health problems among participants. Based on the aim of this study, we selected the following life adversities: history of sleeping on the streets, taking illicit drugs, physical abuse and sexual abuse (both as a child and as a young adult), and reported bullying during childhood. Chi-square tests were used to explore the relationship between these childhood adversities and the mental health variables of current depression and suicide attempts or self-harm. The latter two variables were distinguished by the reported intent.

\section{Results}

A substantial proportion (28.7\%) of the sample had 'attempted suicide' at some point during their lives. More than half (56.6\%) scored highly on the depressed mood item of the HoNOS. The frequencies of different life adversities were: physical abuse as a child $36.7 \%$, as an adult $21.3 \%$; sexual abuse as a child $16.7 \%$, as an adult $12.0 \%$; sleeping on the street $25.3 \%$; taking drugs $72 \%$; and being bullied as a child $47.3 \%$. These are high incidence rates of traumas both as children and as young adults.

A history of sleeping on the streets was associated with attempting suicide $(P=0.003)$ but not with current depressed mood. No association was found between suicide attempts and drug misuse. Nevertheless, substance misuse was associated with both depressed $\operatorname{mood}(P=0.035)$ and selfharm $(P=0.014)$.

Bullying was not associated with any mental health problems.

\section{Table 1}

Association between physical abuse and psychiatric variables

\begin{tabular}{|l|r|l|l|}
\hline $\begin{array}{l}\text { Tested associations with physical abuse as a } \\
\text { child/adult }\end{array}$ & $\chi^{2}$ & d.f. & $P$ \\
\hline Physical abuse as a child & & & \\
\hline Attempted suicide & 2.733 & 1 & 0.098 \\
\hline Self-harm (HoNOS) & 7.231 & 4 & NS \\
\hline Depressed mood (HoNOS) & 11.850 & 4 & 0.019 \\
\hline Physical abuse as an adult & & & \\
\hline Attempted suicide & 9.722 & 1 & 0.002 \\
\hline Self-harm (HoNOS) & 6.238 & 4 & NS \\
\hline Depressed mood (HoNOS) & 14.112 & 4 & 0.007 \\
\hline
\end{tabular}


Table 2

Association between sexual abuse and psychiatric variables

\begin{tabular}{|l|l|l|l|}
\hline $\begin{array}{l}\text { Tested associations with sexual abuse as a } \\
\text { child/adult }\end{array}$ & $\chi^{2}$ & d.f. & $P$ \\
\hline Sexual abuse as a child & & & \\
\hline Attempted suicide & 5.440 & 1 & 0.020 \\
\hline Self-harm (HoNOS) & 8.920 & 4 & 0.063 \\
\hline Depressed mood & 3.147 & 4 & NS \\
\hline Sexual abuse as an adult & & & \\
\hline Attempted suicide & 5.036 & 1 & 0.025 \\
\hline Self-harm (HoNOS) & 3.628 & 4 & NS \\
\hline Depressed mood & 5.161 & 4 & NS \\
\hline
\end{tabular}

Having been abused as both a child and an adult was significantly associated with high scores for depressed $\operatorname{mood}(P=0.019$ and $P=0.007$ respectively). In addition, physical abuse as an adult was associated with a history of suicide attempts $(P=0.002)$ (Table 1). Sexual abuse as both a child and as an adult was also strongly associated with attempted suicide $(P=0.020$ and $P=0.025$ respectively) (Table 2).

\section{Discussion}

The rates of depression and other psychiatric disorders are significantly elevated among the homeless population (West, 1999). Our study revealed high levels of mental health needs among a group of young homeless people. The underlying mechanisms are complex, and a number of vulnerability factors appear to be involved. Abusive experiences during earlier and later life were significantly associated with depressed mood and suicide attempts. In another UK study, twofifths of people who had fled physical violence at their parental home had depression or anxiety, in comparison with less than one-fifth of those who became homeless for other reasons (Nassor \& Brugger, 2000).

Despite a body of evidence on the high prevalence of psychiatric disorders among homeless youth, less is known about its long-term course and the impact of early and subsequent risk factors (Nassor \& Brugger, 2000). In this study, we have found a number of significant associations between life adversities experienced by homeless young adults and psychiatric presentations.

Homeless youths present challenges to both psychiatric and other services. There is a need for better interventions and prevention. There is a compelling need for researchers and policy-makers to make efforts to work collaboratively to improve policy, informed by research findings (Kidd \& Davidson, 2006). However, this joint endeavour to address sociopolitical issues to influence mental health outcomes for these youths could be made acrimonious by the current economic and political situation.
There are a number of limitations in this study that need to be acknowledged. A retrospective study can be subject to recall bias. The lack of geographical stability, the priority of meeting their basic needs, and legal and ethical complexities have constrained previous research with homeless young people, hence a strength of this study was to obtain a reasonably large sample. This should not deter us from attempting longitudinal research in this area to replicate and substantiate these findings, as well as to shed further light on the interaction between risk factors and mental health. Other limitations of this study are the potential for bias through the use of a clinician-rated tool (the HoNOS), rather than independent diagnostic interviews or self-rated measures.

The needs of this often forgotten group cannot be met by any single agency (Craig \& Hodson, 2000; Taylor et al, 2006). Hence there is a well-documented gap in transitional generic psychiatric services for older adolescents/young adults, with problems being multiplied for this vulnerable group. Despite the need for new services, a better skill base and transitional arrangements, the current economic climate worldwide means that the need of this politically weaker section of society is easily moved to the bottom of the priority list of any policy-makers, especially when the resources of the public services are stretched to their limit.

\section{References}

Craig, T. \& Hodson, S. (2000) Homeless youth in London: II. Accommodation, employment and health outcomes at 1 year. Psychological Medicine, 30, 187-194.

Herman, D. S. W., Ezra, S., Susser, M. D., et al (1994) Childhood out of home care and current depressive symptoms among homeless adults. American Journal of Public Health, 84, 1849-1851.

Kanth, A. K. (2004) Street children and homelessness. Cyc-Online, issue 68. Available at http://www.cyc-net.org/cyc-online/cycol-0904Homelessness.html (accessed March 2012).

Kidd, S. A. \& Davidson, L. (2006) Youth homelessness - a call for partnerships between research and policy. Canadian Journal of Public Health - Revue Canadienne De Sante Publique, 97, 445-447.

Kimberly, R., Ryan, K., Ana Mari, C., et al (2000) Psychological consequences of child maltreatment in homeless adolescents: untangling the unique effects of maltreatment and family environment. Child Abuse and Neglect, 24, 333-352.

Nassor, A. \& Brugger, A. (2000) Centrepoint Factsheet Series 1999/2000. Centrepoint. Available at http://www.centrepoint.org.uk (accessed 2011)

Taylor, H., Stuttaford, M., Broad, B., et al (2006) Why a roof is not enough: the characteristics of young homeless people referred to designated mental health service. Journal of Mental Health, 15, 491-501.

Tyler, K. A. (2006) A qualitative study of early family histories and transitions of homeless youth. Journal of Interpersonal Violence, 21, 1385-1393.

West, P. (1999) Youth. In Inequalities in Health: The Evidence Presented to the Independent Inquiry into Inequalities in Health, Chaired by Sir Donald Acheson (eds D. Gordon, M. Shaw, D. Dorling, et al), pp. 12-22. Policy Press.

Wing, J. K., Beevor, A. S., Curtis, R. H., et al (1998) Health of the nation outcome scales (HoNOS): research and development. British Journal of Psychiatry, 172, 11-18.

Wing, J. K., Lelliott, P. \& Beevor, A. S. (2000) Progress on HoNOS British Journal of Psychiatry, 176, 392-393. 